\title{
Development of an Ungulate Mammalian Hair Key
}

\author{
Patrick Jones, Sophie Sfez, and Peter T. Knamiller \\ Department of Ecology, University of Alberta
}

We have created a dichotomous hair key to differentiate between adult and juvenile ungulates seen in summer wolf diets; however we would like to stress that this key can also be used for other large carnivore diets, as it has shown merit in the identification of cougar and coyote prey items. To our knowledge there is no mammalian hair key that is able to sufficiently differentiate between juvenile and adults of the major species in the North American Wolf's (Canis lupus) diet, specifically, mule deer, white-tailed deer, elk, moose and bighorn sheep. We acquired juvenile hair samples starting at birth at bi-weekly to monthly intervals from various zoos, wildlife parks and rehabilitation centres over North America for all the major prey species except bighorn sheep. Main characters used to classify ungulate hair were basal scale margin distance, hair diameter and hair color. Scale margin distance and basal hair diameter was measured via a microscope ocular micrometer, with t-tests completed to assess differences between species. We were successful at differentiating between all juvenile ungulates, however juvenile deer species hair maybe very difficult to differentiate between and may only be accurately done with experience. Juvenile ungulate hair is usually smaller in diameter then the guard hair of adults and is more delicate in appearance. As observed in other study by De Marinis et al 2006, we too were able to differentiate juvenile ungulates by a scalloped medulla (Figure 1). We were able to distinguish juvenile moose by their ginger color appearance, large medial hair cuticle scales, and large basal hair diameter compared to other ungulate species (Figure 2). We also found the juvenile elk had smaller hair diameters then juvenile deer and appear less ridged compared to juvenile deer.

If you have any questions regarding the hair key or would like to view it, please contact Patrick Jones at pj2@ualberta.ca.

\section{REFERENCES}

De Marinis, A.M. and A. Asprea. 2006. Hair identification key of wild and domestic ungulates from southern Europe. - Wildl. Biol. 12: 305-320.

Harrison, R. L. 2002. Evaluation of microscopic and macroscopic methods to identify felid hair. Wildlife Society Bulletin, 30(2): 412-419

Kennedy, A.J. and L. N Carbyn. Identification of wolf prey using hair and heather remains with special ref- erence to Western Canadian National Parks. Canadian Wildlife Service. Edmonton, AB.

Moore, T. D., Spence, L. E., Dugnolle, C. E. and W. G. Hep worth. 1974. Identification of the dorsal guard hairs of some mammals of Wyoming. Wyoming Game and Fish Department Cheyenne, Wyoming.

Wilson, D. E. and D-A. M. Reeder. 2005. A key for the identification of guard hairs of some Ontario mammals. Canadian Journal of Zoology 71:587-591.

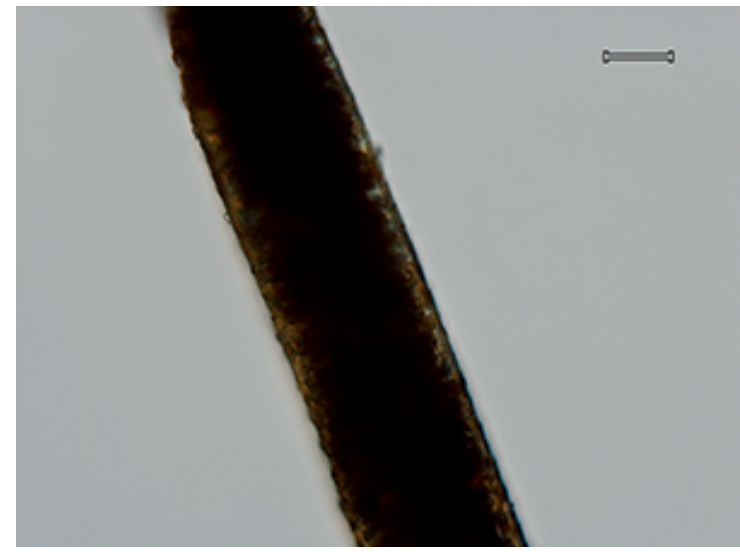

FIG. 1. Juvenile elk medulla, unbroken lattice, scalloped medulla (cortex visible on either side of dark medulla), scale bar: $33.3 \mu \mathrm{m}$. A scalloped medulla is characteristic of most juvenile cervids and Bighorn sheep.

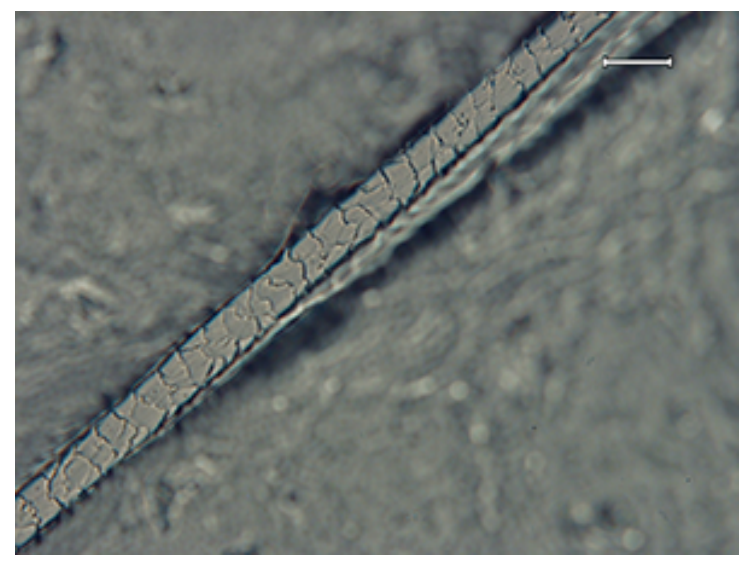

FIG. 2. Juvenile Moose tip, scales distant, margins smoothcrenate, irregular wave mosaic, scale bar: $33.3 \mu \mathrm{m}$. 